UDC 616.24-002.5-085.28:615.015.8]-053.5/.6

https://doi.org/10.52692/1857-0011.2021.3-71.18

\title{
THE COMPARATIVE ANALYSIS OF THE DRUG RESISTANCE OF MBTIN CHILDREN, ADOLESCENTS AND THE SOURCES OF INFECTION IN THE MULTIDRUG-RESISTANT TUBERCULOSIS FOCIES
}

Olha Ivanivna SAKHELASHVILI-BIL, postgraduate student.

Manana Ivanivna SAKHELASHVILI, holder of the habilitated doctor's degree in Medical Science, Professor.

Department of Phthisiology and Pulmonology of Danylo Halytsky Lviv National Medical University. Ukraine

\section{Summary.}

145 patients (67 children and 78 adolescents) from the multidrug-resistant tuberculosis infection focies took part in the complex microbiological study. The children and adolescents had undergone treatment for the pulmonary multidrug-resistant tuberculosis. The study showed that MDR TB was by 1.7 times more often revealed in the adolescents as compared to the children, while the risk of MDR TB was by 3.7 times higher for the children than for the adolescents.

The drug resistance profile of the children and the sources of infection almost completely coincided. The resistance to HRSE (66.1\%) and HRESZ (13.6\%) developed in the adolescents more often than in the children and adults. The study proves the importance of defining the drug resistance profile in the exposed children and adolescents from the multidrug-resistant tuberculosis focies.

Keywords: MRTB, children, adolescents.

Резюме. Сравнительная характеристика лекарстенной устойчивости мбт у детей, подростков и источника инфекции в очагах мультирезистеного туберкулеза

Проведено комплексное микробиологическое обследование 145 детей (67) и подростков (78) из очагов мультирезистентной туберкулезной инфекции. Дети и подростки лечились в связи с мультирезистентным туберкулезом легких (МРТБ). Установлено, что у подростков МРТБ отмечается в 1,7 раза чаще, чем у детей, а риск к МРТБ - в 3,7 раза чаще у детей, чем подростков. У детей констатировано полное совпадение характера устойчивости с источником инфекции, а у подростков чаще всего резистентность отмечено к комбинации HRSE (66,1\%) HRESZ $(13,6 \%)$, в отличии взрослых и детей. Проведенная робота доказывает важность определения профиля резистентности у контактных детей и подростков из очагов мультирезистентной туберкулезной инфекции.

Ключевые слова: МРТБ, дети, подростки.

\section{Introduction.}

At the time when the epidemiological situation of tuberculosis is getting worse, special attention should be paid to children from the tuberculosis infection focies. Of all children and adolescents infected with tuberculosis $45(77.1 \%)$ of them were from the infection focies $[1-3,5,7]$.

The rapid molecular and genetic testing for the drug susceptibility of the MBThas been absolutely crucial today. The wider use and advancement of the molecular and genetic testing for the multidrug resistant tuberculosis will contribute to the early detection of the multidrug resistance in children, adolescents and the sources of infection $[4-6,8]$.

Taking into account that the pulmonary multidrug-resistant tuberculosis and the extensively drug-resistant tuberculosis occurrence has significantly increased in the recent years, the study of the drug resistance profile of MBTin the exposed children and adolescents from the drug-resistant tuberculosis focies has been crucial for providing the most efficient antimycobacterial therapy and preventative care.

\section{The study's objective.}

The drug resistant profile of the MBTin the exposed children, adolescents and the source of infection in the multidrug-resistant tuberculosis focies is the objective of the study.

\section{Materials and methods.}

145 children from Lviv region, Ukraine were examined to take part in the microbiological study. The patients aged under 14 were classified as "children" (67) and those aged 15-17 were classified as "adolescents" (78). All the children and adolescents were from the multidrug-resistant tuberculosis focies. They had undergone treatment for the multidrug-resistant pulmonary tuberculosis at the Pediatric Department of Lviv Pulmonary Health Center throughout the period of 2012-2021.

The microbiological study with the involvement of the children, adolescents and adult patients included the detection of the MBTby the sputum smear microscopy, sputum culturing on the Lowenstein-Jensen medium, the classification of the released mycobacteria in BACTEC MGIT 960 and 
testing for the drug susceptibility of the MBTto the first-line and second-line antimycobacterial agents. The molecular-genetic analysis of sputum, in particular, GeneXpert MBT/RIF and the line-probe assay of Hain Lifesciences, were applied for diagnosing the multidrug-resistant tuberculosis. The objective was to define the susceptibility of the MBTto the first-line antimycobacterial agents (isoniazid and rifampicin) by applying GenoTyp MTBDRplus hybridization instruments, as well as to the second-line agents (fluoroquinolones and aminoglycosides) by applying the GenoTyp MTBDRsl hybridization instruments.

The medical records of 102 adult patients serving as the sources of infection were analyzed retrospectively to study the drug resistance profile of the MBTin the multidrug-resistant tuberculosis focies. The patients had undergone treatment for tuberculosis at the relevant health care settings of Lviv region. The annual reports of the health care settings in Lviv region providing treatment for tuberculosis (33 on the TB patients made by the Ministry of Health of Ukraine") and the analysis of medical journals of drug-resistant tuberculosis kept by the Central Medical Consultative Board were used for the study.

\section{Results and discussion.}

The study proved that the tuberculosis occurrence in the multidrug-resistant TB focies had increased by
2.7 times (from 7.7 to 20.2 per 1,000 exposed people, $\mathrm{p}<0.01$ ). It should be noted that $23.8 \%$ of the children under the age of one and $59.6 \%$ of the children under the age of four wee infected. The patients aged 17 prevailed among the adolescents (Figure 1).

The age structure of the adolescents: over half $(52.5 \%)$ of the adolescents in the main group were 17 years old, $10.3 \%$ were aged 15 and $37.2 \%$ were aged 16 .

The bacteriological examination of the infected exposed children proved that $47.8 \%$ of them didn't discharge bacteria and were referred to the group with the risk of the multidrug-resistant tuberculosis based on the type of the multidrug-resistant TB site. The multidrug-resistance in the form of the multidrug-resistant tuberculosis and the pre-extensive drug-resistance (pre-extensive drug resistance - MDR-TB + fluoroquinolones) was evident in 35 children (52.2\%), while the risk of the multidrug-resistant tuberculosis was revealed in 32 cases $(47.7 \%)$.

At the same time, the multidrug-resistant tuberculosis was revealed in the adolescents by 6.7 times more often than the risk of the multidrug-resistant tuberculosis $(87.7 \%$ versus $12.8 \%, \mathrm{p}<0.001)$ as compared to the children. The multidrug-resistant tuberculosis was by 1.7 times more often revealed in the adolescents $(87.7 \%$ versus $52.2 \%, \mathrm{p}<0.05$, Figure 2$)$.

Figure 2 shows that the multidrug-resistant tuberculosis was by 1.7 times more often diagnosed in the

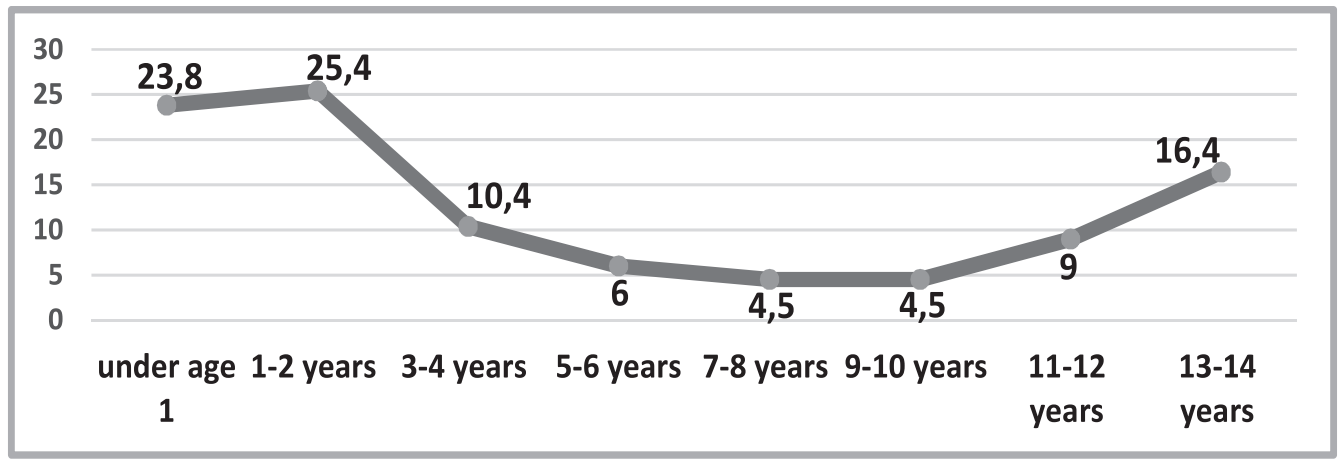

Figure 1. The age structure of the examined children

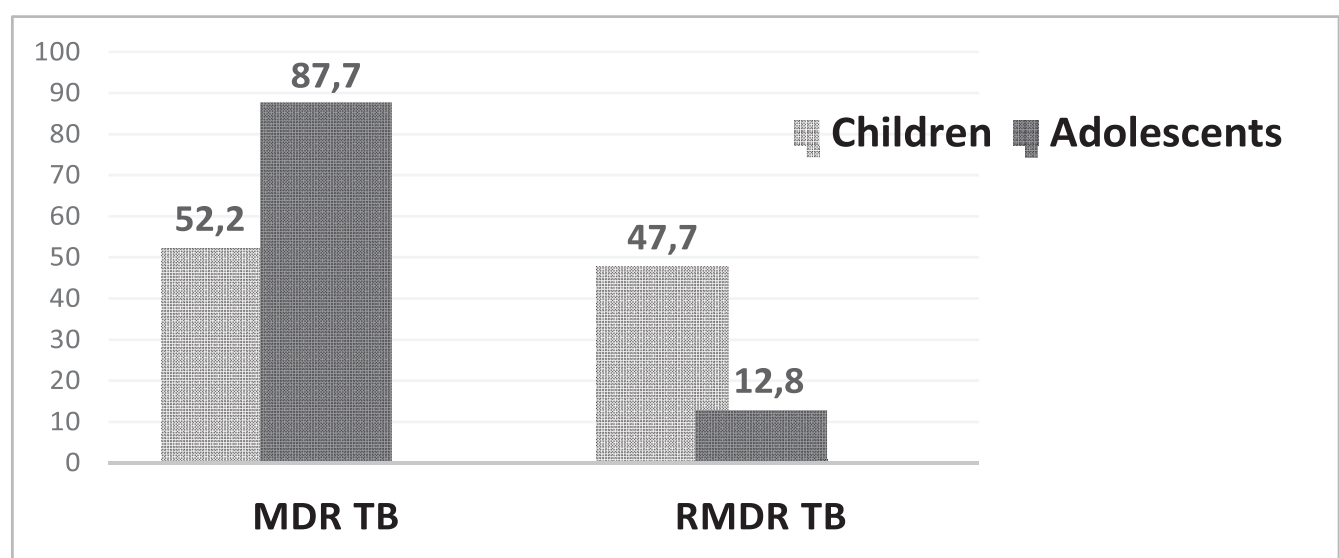

Figure 2. The results of testing for the drug susceptibility of the MBT(MBT) to antimycobacterial agents among the children and adolescents of the main group (\%). 


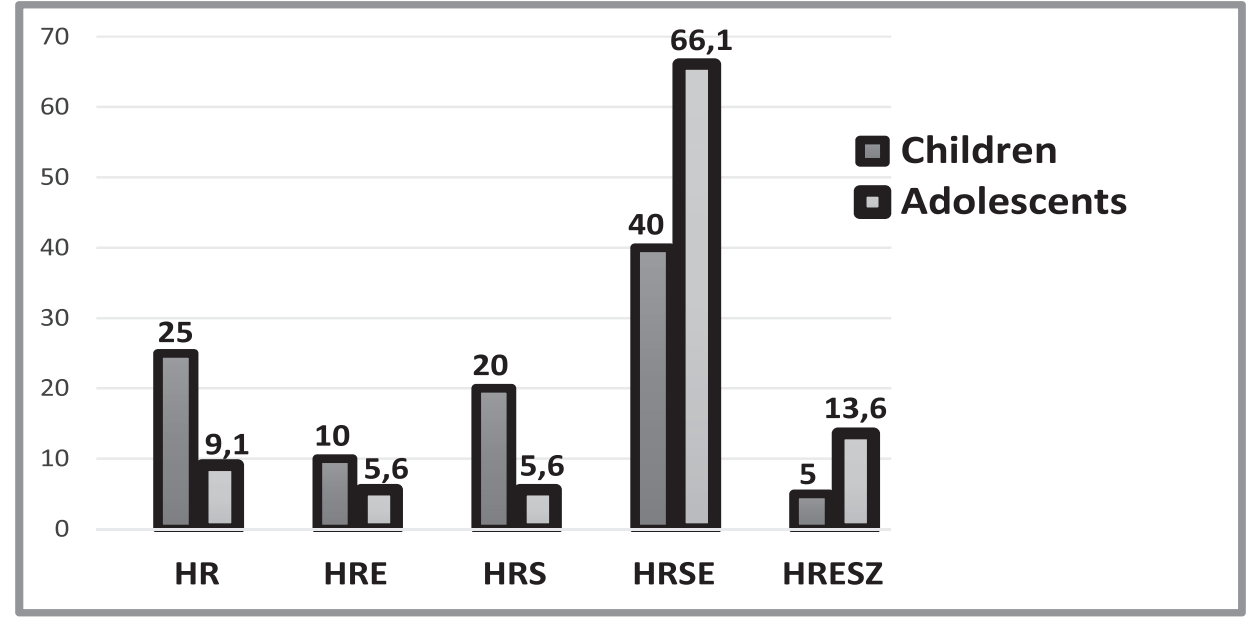

Figure 3. The drug resistance profile of MBTstrains (\%).

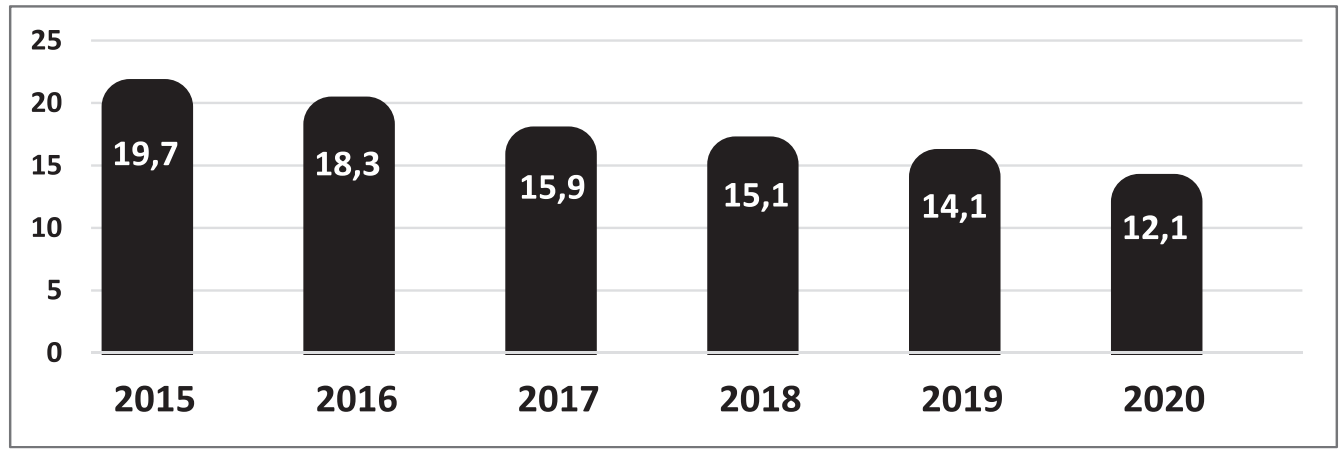

Figure 4. The course of the multidrug-resistant tuberculosis among the population of Ukraine throughout the period of 2015-2020 (per 100,000 people).

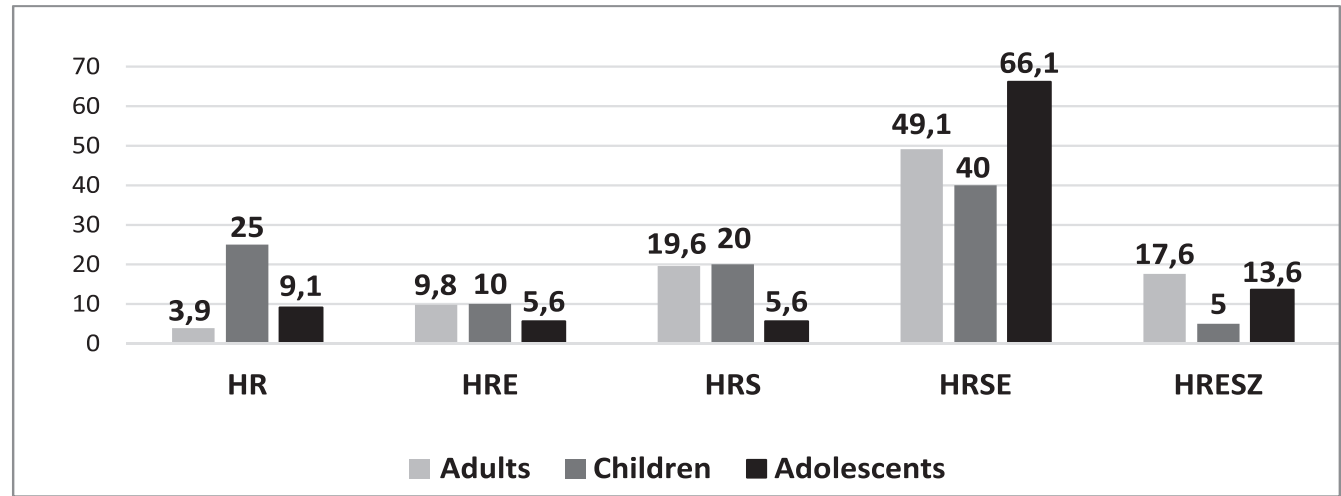

Figure 5. The comparative analysis of the drug resistance profile in the children, adolescents and adults (\%).

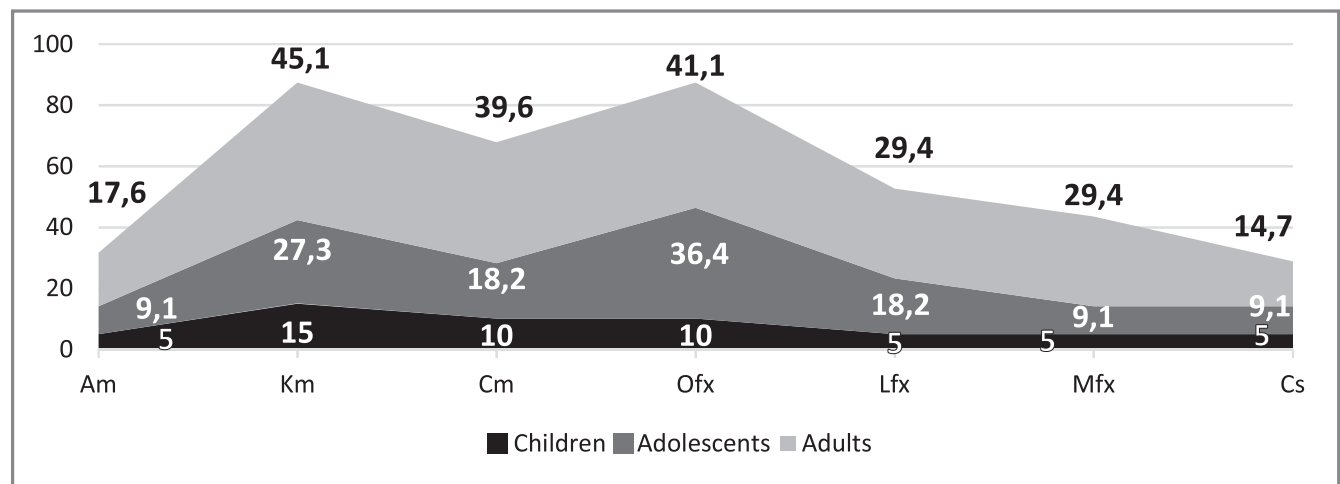

Figure 6. The comparative analysis of the drug resistance rate to the second-line agents developed in the children, adolescents and adults serving as the sources of infection (\%). 
adolescents than in the children $(\mathrm{p}<0.05)$, while the risk of the multidrug-resistant tuberculosis was by 3.7 times higher for the children than for the adolescents $(\mathrm{p}<0.01)$.

The resistance to HR was by 2.7 times higher ( $25 \%$ versus $9.1 \%, p>0.01$ ), resistance to HRE was by 1.8 times higher $(10.0 \%$ versus $5.6 \%, \mathrm{p}>0.05)$ and resistance to HRS was by 3.5 times higher $(20.0 \%$ versus $5.6 \%, \mathrm{p}>0.01$ ) among the children as compared to the adolescents, while the resistance to HRESZ was by 2.7 times less often revealed (5.0\% versus $13.6 \%$, $\mathrm{p}>0.01)$ and resistance to HRES was by 1.6 times less often detected ( $40.0 \%$ and $66.1 \%, \mathrm{p}>0.05$, Figure 3 ). The resistance to the second-line agents was by $2-3$ times more often detected in the adolescents as compared to the children (Figure 3).

Most exposed children and adolescents (65.6\% and $61.5 \%$ ) were diagnosed with the multidrug-resistant tuberculosis during their visits to General Practitioners. Widespread tuberculosis was revealed both in the children (44.7\%) and adolescents (59.0\%), but the moderate and severe forms were by 1.3 times less often revealed among the adolescents as compared to the children. Over one third of the children from the multidrug-resistant tuberculosis focies (35.8\%) had not been vaccinated in the maternity hospitals and the exposed children had not been provided with any preventative care.

The analysis of the multidrug-resistant tuberculosis incidence was made among the adult population of Lviv region. According to Figure 4, the detection rate of the multidrug-resistant tuberculosis among the adults of Lviv region decreased by 1.6 times throughout the period of 2015-2020 (from 19.7 to 12.1 per 100,000 people). It could be caused by the healthcare reform in Ukraine, the reduction of healthcare facilities providing treatment for phthisiological disease and the less attention paid by General Practitioners to tuberculosis due to the COVID-19 pandemic.

One should note that the multidrug-resistant tuberculosis rate decreased by 1.6 times $(19.7 \%$ versus $12.1 \%, \mathrm{p}>0.05)$ as compared to 2015 . At the same time, the extensively drug-resistant tuberculosis rate increased by 1.6 times. The study of the multidrug-resistant tuberculosis focies showed that the children and adolescents were the most often infected by their fathers $(59.8 \%)$. Mothers infected their children and adolescents by 3 times less often $(20.0 \%, p<0.01)$, grandfathers and grandmothers served as the infection sources even less often $(4.0 \%$ and $3.0 \%$ correspondingly). It should be noted that the children and adolescents were more often in the regular other than intermittent contacts with their family members $(88.1 \%)$.
$47.0 \%$ of the infected adults serving as the sources of the infection were diagnosed with the multidrug-resistant tuberculosis for the first time. In some cases the extensively drug-resistant tuberculosis was revealed during the recurrence $(33.3 \%)$ and after the ineffective treatment (34.8\%).

Figure 8 gives the gender based analysis of patients with the pulmonary MDR TB who served as the sources of the infection. The men prevailed in the group selected for the examination by 3.8 times (79.1\% versus $20.9 \%$ ). Most infected women (56.7\%) were the age of 20-29. The amount of infected women at the age of 30 and more was by 8 times less (up to $6.6 \%)$. At the same time, men more often got infected at the age of 30 and more $(93.1 \%, \mathrm{p}<0.001)$, the highest infection rate was revealed in the men at the age of 30-39 (52.7\%).

The social analysis of the patients with the pulmonary MDR TB revealed the substantial amount of unemployed people $(74.5 \%)$ and released prisoners (13.7\%) (Figure 5).

The analysis of the drug resistance profile of the MBT in the multidrug-resistant infection focies revealed almost complete coincidence of the drug resistance profile developed in the children and the sources of infection. Adolescents developed resistance to HRSE (66.1\%) and HRESZ (13.6\%) more often than adults and children (Figure 6).

The analysis of the drug resistance rate to the second-line agents showed that in most cases the resistance to kanamycin and capreomycin $(\mathrm{Km}-15.05 \%$ and $\mathrm{Cm}$ $-10.0 \%$ ) was revealed in the children (Figure 6).

Consequently, our study proves the importance of defining the drug resistance profile in the exposed children from the multidrug-resistant tuberculosis focies for providing them with the most effective antimycobacterial therapy and further preventative care. The importance of the study is also confirmed by different research conducted by the national and foreign scientists [1-4].

\section{Conclusions.}

$3.8 \%$ of all the infected children from the multidrug-resistant tuberculosis focies were under the age of 1 and $59.6 \%$ of the children were under the age of 4. Patients aged 17 prevailed among the adolescents.

The exposed children developed resistance to HRS, HR and HRE more often than the infected adolescents (by 3.5, 2.7 and 1.8 times correspondingly), while resistance to HRESZ and HRES was by 2.7 and 1.6 times (correspondingly) less often revealed. The resistance to HRSE (66.1\%) and HRESZ (13.6\%) was the most often revealed in the adolescents than in the sources of infection and children. 
Most exposed children and adolescents were diagnosed with the multidrug-resistant tuberculosis $(65.6 \%$ and 61.55$)$ during their visits to General Practitioners. At the same time, the widespread tuberculosis was revealed both in the children $(44.7 \%)$ and adolescents (59.0\%). Over one third of the children from the multidrug-resistant tuberculosis focies (35.8\%) had not been vaccinated in the maternity hospitals and the exposed children had not been provided with any preventative care.

In most cases fathers served as the sources of the infection in the multidrug-resistant tuberculosis focies in $59.8 \%$ cases, mothers infected their children and adolescents by 3 times less often $(20 \%, p<0.01)$, grandfathers and grandmothers served as the sources of infection even less often ( $4.0 \%$ and $3.0 \%$ correspondingly). In most cases, the children and adolescents were in the regular other than intermittent contacts with their family members $(88.1 \%$ versus $11.9 \%)$.

The drug resistance profile of the MBT in the multidrug-resistant tuberculosis focies almost completely coincided in the children and the sources of infection. Nevertheless, the adolescents developed resistance to HRSE (66.1\%) and HRESZ (13.6\%) more often than the adults and children.

\section{Literature}

1. V.A. Aksionova, N.I. Klevno, S.M. Kavtarashvili and others. Tuberculosis infection site as the risk of multi- drug-resistant tuberculosis for children. Tuberculosis and Lung Diseases, 2018; Vol.96.(1):11-1.DOI: https://DOI. org/ 10. 21292/2075-1230-2018-96(1):11-7.

2. O.I. Bilohortseva, L.A. Sukhanova, I.Y. Shekhter and others. Multidrug-resistant tuberculosis in Ukraine versus the general tuberculosis incidence./Ukrainian Pulmonology Journal, 2019, 1. Enclosure: 15-20.

3. M.I. Sakhelashvili, I.L. Platonova, T.M. Balyta and others. Tuberculosis occurrence and tuberculosis profile among children and adolescents from the tuberculosis infection focies. Tuberculosis, pulmonary diseases, HIV-infection. 2012;2(9): 99-95.

4. Y.I. Feshechenko, V.M. Melnyk, M. Humeniuk, M.I. Lynnyk The Epidemiological situation of tuberculosis in Ukraine. Infusion \& Chemotherapy,2019;4:5-9. DOI: https://doi.org/ 10.32902/2663-0338-2019-4-5-9.

5. Becerra, Mercedes C. ScD, et al. Tuberculosis in Children Exposed at Home to Multidrug-resistant Tuberculosis The Pediatric Infectious Disease Journal: February 2013; Vol.32,Issue 2:115-119. DOI: 10.1097/ INF.0b013e31826f6063.

6. Bielecka T. et al. Recommendations for the management of tuberculosis in children - kompass TB. Part 1: Tuberculosis prevention. Adv Respir Med. 2018; 149-7.

7. James A Seddon et al. Multidrug-resistant tuberculosis in children and adolescents: current strategies for prevention and treatment. Expert Review of Respiratory Medicine. 2020; 221-237., Published online: 10 Oct 2020.

8. H. Simon Schaaf, and Ben J. Marais. The Role of Xpert MTB/RIF Ultra in Diagnosing Pulmonary Tuberculosis in Children. American J. of Respiratory and Critical Care Medicine. PubMed: 31386819. 